\title{
Comprehensive Analysis of Red Blood Cell Distribution Width as a Preoperative Prognostic Predictor in Gastric Cancer
}

\author{
NORIYUKI HIRAHARA, YOSHITSUGU TAJIMA, YUSUKE FUJII, SHUNSUKE KAJI, \\ TETSU YAMAMOTO, RYOJI HYAKUDOMI, TAKAHITO TANIURA and YASUNARI KAWABATA \\ Department of Digestive and General Surgery, Shimane University Faculty of Medicine, Izumo, Japan
}

\begin{abstract}
Background/Aim: The aim of the current study was to investigate the impact of the preoperative red cell distribution width $(R D W)$ value on the overall survival $(O S)$ and cancer-specific survival (CSS) of gastric cancer patients. Patients and Methods: A total of 366 gastric cancer patients who underwent curative gastrectomy were retrospectively reviewed. Among them, RDW was evaluated in 165 nonelderly and 201 elderly patients. Results: Multivariate analysis revealed that pathological stage (pStage), RDW, and carcinoembryonic antigen (CEA), were independent prognostic factors of $O S$, while pStage and RDW were independent prognostic factors of CSS. In non-elderly patients, based on the multivariate analysis, pStage, adjuvant chemotherapy, and $R D W$ were identified as independent prognostic factors of OS. In elderly patients, RDW was identified as independent prognostic factors of OS and CSS. Conclusion: Preoperative RDW is a promising independent prognostic factor in gastric cancer.
\end{abstract}

Gastric cancer, one of the most common malignant tumors of the digestive tract, continues to be a major health problem worldwide. In 2012, gastric cancer was ranked fifth and third considering the worldwide incidence and mortality, respectively (1). Gastric cancer is either asymptomatic or causes nonspecific symptoms in its early stages. Therefore, screening for gastric cancer is not always effective, and it is often diagnosed at an advanced stage (2). The lack of specific, reliable tumor markers for gastric cancer is a primary cause of delay in its definitive diagnosis. To establish adequate treatment strategies for individual patients

Correspondence to: Noriyuki Hirahara, MD, Ph.D., Department of Digestive and General Surgery, Shimane University Faculty of Medicine, 89-1 Enya-cho, Izumo, Shimane 693-8501, Japan. Tel: +81 853202232, Fax: +81 853202229, e-mail: norinorihirahara@ yahoo.co.jp

Key Words: Gastric cancer, red blood cell distribution width, prognostic factor. with gastric cancer, precise patient stratification using reliable biomarkers is necessary.

Red cell distribution width (RDW) is an index of the heterogeneity in the size of circulating erythrocytes, and an elevated RDW is used to quantitate the extent of anisocytosis in peripheral blood. RDW is thus conventionally utilized for differentiating types of anemia in clinical practice. However, recent studies have demonstrated that RDW may also reflect the extent of patient's physiological reserve, tumor-associated inflammation, and poor nutritional status (3-7). Meanwhile, only a few studies have focused on RDW in the field of oncology $(5,6,8,9)$. In predicting the recurrence or prognosis of patients with gastric cancer, several tumor biomarkers, such as carcinoembryonic antigen (CEA), p53, programmed cell deathL1 (PD-L1), microsatellite instability (MSI), K-RAS, and BRAF, are used individually or in combination with each other. However, the use of these biomarkers is expensive and not well standardized, with limited availability (10-12). Therefore, there is a significant need to identify more valid, reliable, and accessible prognostic biomarkers for gastric cancer.

Thus, the aim of the current study was to investigate the impact of the preoperative RDW value on the overall survival (OS) and cancer-specific survival (CSS) of patients with gastric cancer.

\section{Patients and Methods}

Patients. This study was based on retrospective analysis of 366 patients with gastric adenocarcinoma who underwent curative laparoscopic (assisted) gastrectomy at our institute between January 2010 and December 2016. Gastric cancer patient who was operated without grasping the cancer cite with forceps was regarded as indication for laparoscopic surgery. The inclusion criteria were as follows: 1) age 20-89 years, 2) histologically verified gastric adenocarcinoma, 3) no distant metastasis, 4) an Eastern Cooperative Oncology Group performance status of 0-2, and 5) curative gastrectomy with R0 resection. R0 resection was defined as a complete resection of the tumor with no microscopic margin involvement. Patients were excluded if they had remnant gastric cancer, an emergency gastrectomy for bleeding or perforation, and hematological, inflammatory, or autoimmune disorders. There was no patient who died of complications related to surgery within 30 
days. The requirement for informed consent was waived, because this study was retrospective. All procedures were approved by the Institutional Review Board (IRB) (UMIN:000030472).

Laparoscopic gastrectomy. As the basic procedure, early gastric cancer with lesions localized at the upper part of the stomach were treated by proximal gastrectomy and double-tract reconstruction, while early gastric cancer with lesions spreading in the upper and middle regions and advanced gastric cancer with lesions located at the upper region were subjected to total gastrectomy and Roux-en-Y reconstruction. Distal gastrectomy was selected when a satisfactory proximal resection margin can be obtained. The first choice of reconstruction was performed by Billroth I method, and when the residual stomach and duodenum was not reached, Roux-en Y method was performed. The extent of lymph node dissection was carried out according to the Japanese Gastric Cancer Treatment Guideline (version 3) (13); total gastrectomy was performed in 79 patients, proximal gastrectomy in 37 patients, and distal gastrectomy in 250 patients (Table I).

Outcome evaluation. OS and CSS were evaluated, and the cause of death determined from the hospital records. OS was calculated from the date of primary gastrectomy to the date of death from any cause or the last follow-up, and CSS was defined as the interval from the date of surgery to cancer-specific death. This retrospective study was conducted in accordance with the Declaration of Helsinki.

$R D W$. The RDW is a measurement derived from red blood cell distribution curves, which contains RDW-CV (RDW coefficient of variation) and RDW-SD (RDW standard deviation) values that reflect the extent of heterogeneity. The RDW-CV is calculated based on both the width of the distribution curve and the mean cell size, using the following formula: $\mathrm{RDW}=$ (one standard deviation of red cell volume/mean cell volume) $\times 100$. RDW-CV is reported as a \% with a reference range of approximately $11.0 \%-15.0 \%$. On the other hand, the RDW-SD is an actual measurement of the width of the red cell distribution curve in femtoliters (fL), and it is measured at the point that is $20 \%$ above the baseline. Since RDW-SD more accurately reflects the red cell size variance, RDW-SD was treated as the prognostic value of RDW for analysis (14). The routine reference cutoff value for RDW used in our hospital laboratory was $<50$.

Tumor staging. The pathological classification was determined according to the Japanese classification of gastric cancer (15).

Statistical analysis. Differences between the study groups were evaluated by using the Student's $t$-test, and differences in continuous variables among the three groups were assessed with the KruskalWallis analysis for non-normally distributed variables. Differences between the clinicopathological features were analyzed by using the chi-square test. The routine reference cut-off value for RDW used in our hospital was 50. An RDW greater than 50 was considered to be high, while RDW of 50 or below was considered to be normal. OS and CSS were calculated according to the Kaplan-Meier method, and the differences between survival curves were assessed by the log-rank test.

Variables with a $p$-value $<0.05$ following the univariate analysis were subjected to multivariate logistic regression analysis. All statistical analyses were performed by using JMP software (version 11 for Windows; SAS Institute); $p$-values $<0.05$ were considered statistically significant.
Table I. Relationships between RDW and clinicopathological features in 366 patients with gastric cancer.

\begin{tabular}{|c|c|c|c|c|}
\hline \multirow[t]{2}{*}{ Characteristics } & \multirow{2}{*}{$\begin{array}{c}\text { Total } \\
\text { patients }\end{array}$} & \multicolumn{2}{|c|}{ RDW } & \multirow[t]{2}{*}{$p$-Value } \\
\hline & & $\begin{array}{c}<50 \\
\mathrm{n}=282(\%)\end{array}$ & $\begin{array}{c}\geq 50 \\
\mathrm{n}=84(\%)\end{array}$ & \\
\hline Age (years old) & & $69.2 \pm 11.3$ & $75.7 \pm 9.2$ & $<0.0001$ \\
\hline Gender & & & & 0.1103 \\
\hline Male & 253 & $189(67.0)$ & $64(76.2)$ & \\
\hline Female & 113 & $93(33.0)$ & $20(23.8)$ & \\
\hline BMI & & $22.39 \pm 3.42$ & $22.52 \pm 3.64$ & 0.7547 \\
\hline WBC $(\mu \mathrm{l})$ & & $5826.5 \pm 1387.1$ & $5550.0 \pm 1623.3$ & 0.1244 \\
\hline $\mathrm{RBC}\left(\times 10^{4} \mu \mathrm{l}\right)$ & & $440.1 \pm 215.7$ & $419.1 \pm 500.9$ & 0.5805 \\
\hline Location of tumor & & & & 0.2508 \\
\hline EGJ & 11 & $7(2.5)$ & $4(4.8)$ & \\
\hline $\mathrm{U}$ & 67 & $49(17.4)$ & $18(21.4)$ & \\
\hline M & 163 & $133(47.2)$ & $30(35.7)$ & \\
\hline $\mathrm{L}$ & 125 & $93(33.0)$ & $32(38.1)$ & \\
\hline Tumor size $(\mathrm{cm})$ & & $4.45 \pm 3.01$ & $5.56 \pm 3.36$ & 0.0043 \\
\hline Procedure & & & & 0.0926 \\
\hline LTG & 79 & $54(19.1)$ & $25(29.8)$ & \\
\hline LPG & 37 & $31(11.0)$ & $6(7.4)$ & \\
\hline L(A)DG & 250 & $197(69.9)$ & $53(63.1)$ & \\
\hline Tumor differentiation & & & & 0.1078 \\
\hline Well & 133 & 97 (34.4) & $36(42.9)$ & \\
\hline Moderate & 162 & $124(44.0)$ & $38(45.2)$ & \\
\hline Poor & 71 & $61(21.6)$ & $10(11.9)$ & \\
\hline Depth of tumor & & & & $<0.0001$ \\
\hline $\mathrm{T} 1 \mathrm{a}-1 \mathrm{~b}$ & 193 & $166(58.9)$ & $27(32.1)$ & \\
\hline 2 & 48 & $38(13.5)$ & $10(11.9)$ & \\
\hline 3 & 53 & $34(12.1)$ & $19(22.6)$ & \\
\hline $4 a-4 b$ & 72 & $44(15.6)$ & $28(33.3)$ & \\
\hline Lymph node metastasis & & & & 0.0003 \\
\hline NO & 246 & $204(72.3)$ & $42(50.0)$ & \\
\hline N1 & 40 & $24(8.5)$ & $16(19.0)$ & \\
\hline $\mathrm{N} 2$ & 42 & $25(8.9)$ & $17(20.2)$ & \\
\hline N3 & 38 & $29(10.3)$ & $9(10.7)$ & \\
\hline Pathological stage & & & & $<0.0001$ \\
\hline $\mathrm{Ia}-\mathrm{Ib}$ & 218 & $189(67.0)$ & $29(34.5)$ & \\
\hline IIa-IIb & 66 & $40(14.2)$ & $26(31.0)$ & \\
\hline IIIa-IIIc & 82 & $53(18.8)$ & $29(34.5)$ & \\
\hline Operation time (min) & & $412.1 \pm 115.2$ & $435.3 \pm 132.2$ & 0.1173 \\
\hline Intraoperative & & & & \\
\hline blood loss (ml) & & $162.0 \pm 303.7$ & $421.8 \pm 823.0$ & $<0.0001$ \\
\hline CEA (ng/ml) & & $4.46 \pm 8.33$ & $7.09 \pm 19.29$ & \\
\hline 0.0736 & & & & \\
\hline Albumin (g/dl) & & $4.03 \pm 0.51$ & $3.52 \pm 0.711$ & $<0.0001$ \\
\hline $\mathrm{CRP}(\mathrm{mg} / \mathrm{l})$ & & $0.288 \pm 0.815$ & $0.626 \pm 1.444$ & 0.0065 \\
\hline Adjuvant chemotherapy & & & & 0.4407 \\
\hline Yes & 97 & $72(25.5)$ & $25(29.8)$ & \\
\hline No & 269 & $210(74.5)$ & $59(70.2)$ & \\
\hline
\end{tabular}

\section{Results}

Association between RDW and clinicopathological features. The relationship between preoperative RDW and clinicopathological features in 366 patients with gastric cancer is shown in Table I. RDW values were significantly 


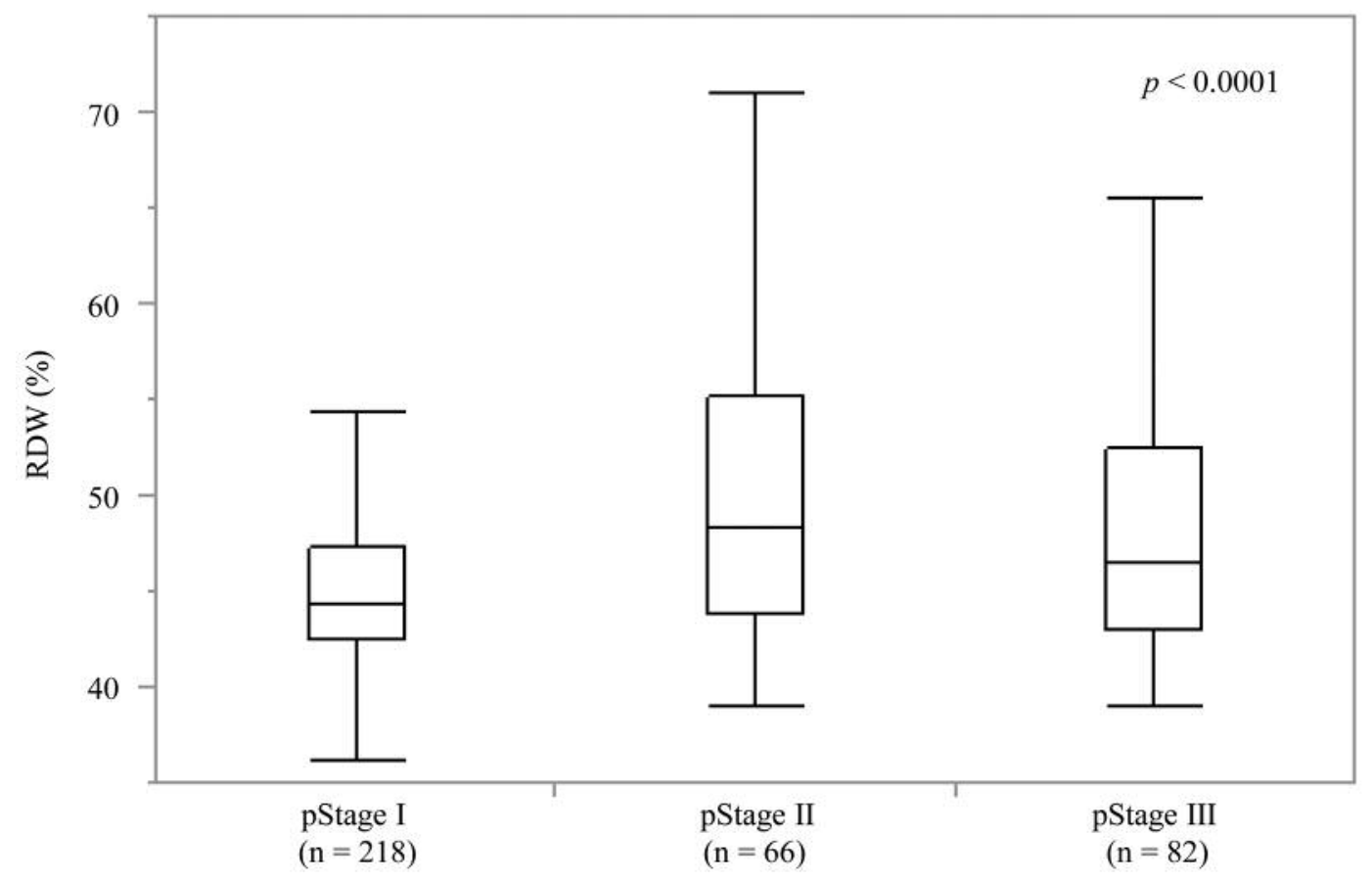

Figure 1.RDW values of all gastric cancer patients according to pStage. In each box plot, the lower and upper ends represent the 25th and 75 th percentiles, respectively. Capped bars indicate the minimum and maximum values, respectively, and the line inside the box represents the median RDW value.

associated with age $(p<0.0001)$, tumor size $(p=0.0043)$, depth of tumor invasion $(p<0.0001)$, lymph node metastasis $(p=0.0003)$, pStage $(p<0.0001)$, intraoperative blood loss $(p<0.0001)$, serum albumin concentration $(p<0.0001)$, and C-reactive protein (CRP) $(p=0.0065)$.

$R D W$ values and pStage. The Kruskal-Wallis one-way analysis indicated that there is a tendency for the proportion of patients with high RDW to be higher in Stage II and III than in Stage I gastric cancer patients. The percentages of high RDW patients were $13.3 \%, 39.4 \%$ and $35.4 \%$ for stage I $(n=218)$, stage II $(n=66)$, and stage III patients $(n=82)$, respectively (Figure 1).

Cox regression analysis for OS and CSS in all patients. As shown in Table II, univariate analyses revealed that age $(p=0.0443)$, pStage $(p<0.0001)$, tumor size $(p=0.0003)$, RDW $(p<0.0001)$, CEA $(p=0.0072)$, tumor differentiation $(p=0.0119)$, and adjuvant chemotherapy $(p=0.0438)$ were significantly associated with OS. Similarly, CSS was also found to be associated with pStage $(p<0.0001)$, tumor size $(p<0.0001)$, RDW ( $p=0.0015)$, CEA $(p=0.0266)$, tumor differentiation $(p=0.0317)$, and adjuvant chemotherapy $(p<0.0001)$. Multivariate analysis revealed that pStage (hazard ratio [HR], 2.254; 95\% confidence interval $[\mathrm{CI}]=1.258-4.069 ; p=0.0063)$, RDW $(\mathrm{HR}=2.840 ; 95 \% \mathrm{CI}=1.771-4.533 ; p<0.0001)$, CEA
$(\mathrm{HR}=1.723 ; 95 \% \mathrm{CI}=1.070-2.719 ; p=0.0259)$, and tumor differentiation $(\mathrm{HR}=1.654 ; 95 \% \mathrm{CI}=1.050-2.628 ; p=0.0297)$ were independent prognostic factors of OS. Further, pStage $(\mathrm{HR}=5.292 ; 95 \% \mathrm{CI}=2.203-13.519 ; p=0.0001)$ and $\mathrm{RDW}$ $(\mathrm{HR}=2.281 ; 95 \% \mathrm{CI}=1.156-4.040 ; p=0.0181)$ were independent prognostic factors of CSS.

Survival analysis stratified by $R D W$ in all patients. The median follow-up time was 2.8 years (range=0.3-8.1years). The log-rank test demonstrated that patients with a high RDW had a significantly poorer prognosis both in terms of OS $(p<0.0001)$ and CSS $(p=0.0015)$ when compared to patients with a normal RDW (Figure 2).

Association between RDW and clinicopathological features in non-elderly and elderly patients. In non-elderly patients, significant associations were found between RDW and factors such as lymph node metastasis $(p=0.0006)$, operation time $(p=0.0106)$, and serum albumin concentration $(p<0.0001)$ (Table III). In elderly patients, RDW values were significantly associated with tumor size $(p=0.0167)$, depth of tumor invasion $(p=0.0001)$, lymph node metastasis $(p=0.0312)$, pathological tumor, node, metastasis (pTNM) stage $(p<0.0001)$, intraoperative blood loss $(p=0.0005)$, and serum albumin concentration $(p<0.0001)$ (Table IV). 
$R D W$ values and pStage in non-elderly and elderly patients. The Kruskal-Wallis one-way analysis showed that there is a tendency the proportion of non-elderly patients with high RDW to be higher in Stage II and III than in Stage I gastric cancer patients. The percentages of high RDW patients were $8.4 \%, 18.2 \%$ and $19.4 \%$ for stage I $(n=107)$, stage II $(n=22)$, and stage III patients $(n=36)$, respectively (Figure 3a). Similarly, there was a tendency the proportion of elderly patients with high RDW is higher in Stage II and III than in Stage I gastric cancer patients. The percentages of high RDW patients were $18.0 \%, 50.0 \%$ and $47.8 \%$ for stage I $(n=111)$, stage II $(n=44)$, and stage III patients $(n=46)$, respectively (Figure $3 b$ ).

Cox regression analysis for OS and CSS in non-elderly patients. Univariate analyses revealed that pStage $(p<0.0001)$, tumor size $(p=0.007)$, RDW $(p=0.0022)$, and adjuvant chemotherapy $(p=0.0034)$ were significantly associated with OS. Similarly, pStage $(p<0.0001)$, tumor size $(p=0.0019)$, and adjuvant chemotherapy $(p<0.0001)$ were significantly associated with CSS. Based on the multivariate analysis, pStage $\quad(\mathrm{HR}=11.856 ; \quad 95 \% \mathrm{CI}=3.791-38.066$; $p<0.0001)$ and $\mathrm{RDW}(\mathrm{HR}=3.400 ; 95 \% \mathrm{CI}=1.339-8.154$; $p=0.0114$ ) were identified as independent prognostic factors of OS, while pStage $(\mathrm{HR}=25.871 ; 95 \% \mathrm{CI}=5.958-118.999$; $p=0.0001)$ was found as the only independent prognostic factor of CSS (Table V).

Cox regression analysis for OS and CSS in elderly patients. Univariate analyses revealed that while OS was significantly associated with pStage $(p=0.0262)$, tumor size $(p=0.0289)$, RDW $(p=0.0003)$, and tumor differentiation $(p=0.0057)$, CSS was associated with pStage $(p=0.0004)$, tumor size $(p=0.0014)$, RDW $(p=0.0041)$, and adjuvant chemotherapy $(p=0.023)$. Based on a multivariate analysis, RDW $(\mathrm{HR}=2.562$; 95\% CI $=1.447-4.547 ; \quad p=0.0014)$ and differentiation $(\mathrm{HR}=1.971 ; \quad 95 \% \mathrm{CI}=1.128-3.467 ; \quad p=0.0173) \quad$ were identified as independent prognostic factors of OS, while RDW was the only prognostic factor for CSS (HR=2.832; 95\%CI $=1.069-7.958 ; p=0.0363$ ) (Table VI).

Survival analysis stratified by $R D W$ in non-elderly patients. The log-rank test demonstrated that patients with a high RDW had a significantly poorer prognosis in terms of both OS $(p=0.0190)$ and CSS $(p=0.0278)$ when compared to patients with normal RDW (Figure 4).

Survival analysis stratified by RDW in elderly patients. The log-rank test demonstrated that patients with a high RDW had a significantly poorer prognosis in terms of both OS $(p=0.0003)$ and CSS $(p=0.0042)$ when compared to patients with normal RDW (Figure 5).

\section{Discussion}

With accumulating evidence supporting the role of inflammation in carcinogenesis and tumor progression, several serum parameters for systemic inflammation have been shown to be potential predictors of survival in a variety of cancers $(3,4,16)$. Although the exact mechanisms remain unknown, recent studies have suggested that cytokines secreted by inflammatory cells in the tumor microenvironment influence tumor cell proliferation and migration $(17,18)$. RDW is a routinely analyzed parameter in clinical laboratories as a component of the complete blood count to gather information on the heterogeneity in the size of circulating erythrocytes. It essentially reflects the nutritional status of patients, including iron, folate, or vitamin B12 deficient anemia, which are frequently detected in patients with cancer. Furthermore, recent growing evidence indicates that high RDW is a potential predictor of poor survival in various cancers due to close association with tumor-related systemic inflammation (5-9). However, these findings have not been confirmed uniformly, and the impact of routine blood-test markers in the prognosis of gastric cancer is still an ongoing subject of debate. Therefore, the present study aimed to clarify the prognostic value of RDW in gastric cancer patients.

In this study, analysis of patients with gastric cancer revealed a positive association between RDW and tumor size, depth of tumor, lymph node metastasis, pathological stage, intraoperative blood loss, serum albumin concentration, and CRP. These results support the hypothesis that a high RDW reflects tumor-related systemic inflammation and malnutrition induced by more aggressive or progressive cancers. Since there was a tendency for advanced cancer patients to have a low RDW value, possibly there is an association between preoperative RDW and operation time and intraoperative blood loss. Propensity score matched analysis will be necessary in the future. In line with this hypothesis, a significant association between high RDW and unfavorable OS and CSS was also found. Furthermore, Cox multivariate analysis suggested that RDW is an independent prognostic indicator of gastric cancer after curative resection. The mechanism underlying the association between RDW and patient's survival has not been elucidated, but recent studies have revealed that RDW correlates with systemic inflammatory response and malnutrition. Elevated RDW has been reported to be correlated with inflammatory cytokines, such as interleukin-6, tumor necrosis factor-alpha, hepcidin, and other circulating cytokines $(19,20)$. Inflammatory cytokines have been shown to play a role in suppressing the stimulating effect of erythropoietin on bone marrow erythrocyte stem cells, its antiapoptotic effect, and its role in red blood cell maturation. Therefore, more immature red blood cells are released into the peripheral blood circulation, consequently increasing their heterogeneity and 
a

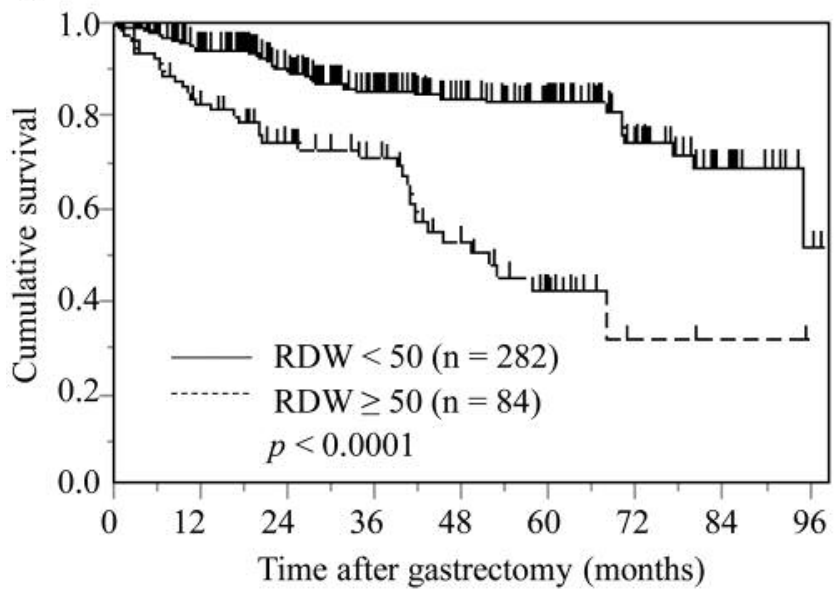

b

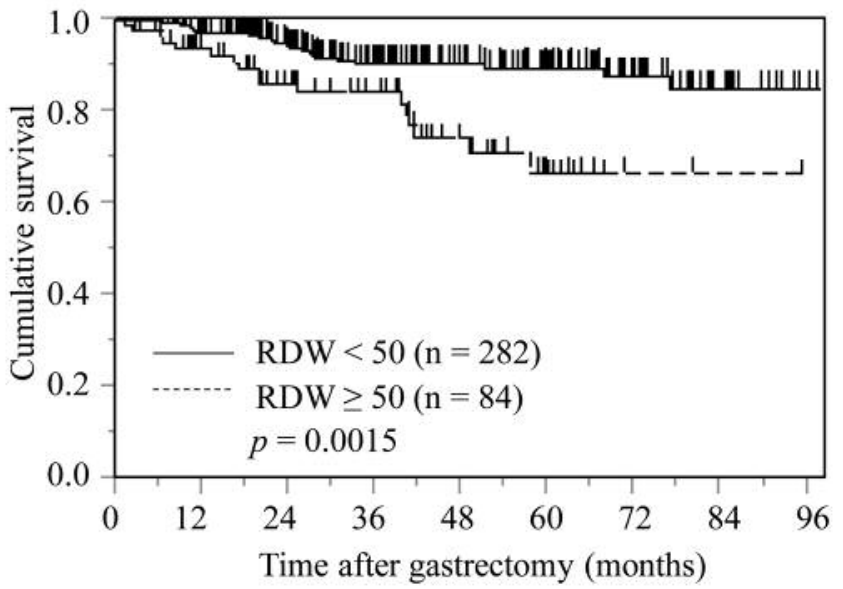

Figure 2. Kaplan-Meier curves of postoperative survival based on RDW of 366 patients with gastric cancer. (a) Overall survival, (b) cancer-specific survival.

Table II. Univariate and multivariate analyses for prognostic factors in overall gastric cancer patients.

\begin{tabular}{|c|c|c|c|c|c|c|c|c|c|c|c|c|}
\hline \multirow[t]{3}{*}{ Variables } & \multicolumn{6}{|c|}{ Overall survival } & \multicolumn{6}{|c|}{ Cancer-specific survival } \\
\hline & \multicolumn{3}{|c|}{ Univariate } & \multicolumn{3}{|c|}{ Multivariate } & \multicolumn{3}{|c|}{ Univariate } & \multicolumn{3}{|c|}{ Multivariate } \\
\hline & HR & $95 \% \mathrm{CI}$ & $p$-Value & HR & $95 \% \mathrm{CI}$ & $p$-Value & HR & $95 \% \mathrm{CI}$ & $p$-Value & HR & $95 \% \mathrm{CI}$ & $p$-Value \\
\hline \multicolumn{13}{|l|}{ Gender } \\
\hline Female/Male & 1.451 & $0.891-2.467$ & 0.1381 & & & & 1.432 & $0.725-3.086$ & 0.3119 & & & \\
\hline \multicolumn{13}{|l|}{ Age } \\
\hline$<70 / \geq 70$ & 1.594 & $1.012-2.571$ & 0.0443 & 1.18 & $0.720-1.968$ & 0.516 & 0.681 & $0.361-1.269$ & 0.2264 & & & \\
\hline \multicolumn{13}{|l|}{ pStage } \\
\hline I, II/III & 3.373 & $2.163-5.234$ & $<0.0001$ & 2.254 & $1.258-4.069$ & 0.0063 & 10.212 & $5.250-21.370$ & $<0.0001$ & 5.292 & 2.203-13.519 & 0.0001 \\
\hline \multicolumn{13}{|l|}{ Tumor size } \\
\hline$<5 / \geq 5$ & 2.247 & $1.443-3.545$ & 0.0003 & 1.371 & $0.785-2.379$ & 0.2653 & 3.975 & $2.044-8.317$ & $<0.0001$ & 1.418 & $0.646-3.302$ & 0.3921 \\
\hline \multicolumn{13}{|l|}{ RDW } \\
\hline$<50 / \geq 50$ & 3.411 & $2.171-5.330$ & $<0.0001$ & 2.84 & $1.771-4.533$ & $<0.0001$ & 2.922 & $1.531-5.472$ & 0.0015 & 2.281 & $1.156-4.040$ & 0.0181 \\
\hline \multicolumn{13}{|l|}{ CEA } \\
\hline$<5.0 / \geq 5.0$ & 1.927 & $1.200-3.027$ & 0.0072 & 1.723 & $1.070-2.719$ & 0.0259 & 2.129 & $1.096-3.995$ & 0.0266 & 1.742 & $0.893-3.283$ & 0.1012 \\
\hline \multicolumn{13}{|l|}{ Diff. } \\
\hline Well \&mod /poor & 1.762 & $1.133-2.766$ & 0.0119 & 1.654 & $1.050-2.628$ & 0.0297 & 1.982 & $1.061-3.803$ & 0.0317 & 1.482 & $0.769-2.925$ & 0.2407 \\
\hline \multicolumn{13}{|l|}{ BMI } \\
\hline$\geq 18.5 /<18.5$ & 1.574 & $0.787-2.853$ & 0.1871 & & & & 0.707 & $0.303-2.060$ & 0.4869 & & & \\
\hline \multicolumn{13}{|l|}{ Adjuvant } \\
\hline $\mathrm{No} / \mathrm{Yes}$ & 1.613 & $1.014-2.522$ & 0.0438 & 0.906 & $0.530-1.527$ & 0.7128 & 4.384 & $2.337-8.515$ & $<0.0001$ & 1.608 & $0.774-3.449$ & 0.2055 \\
\hline
\end{tabular}

Diff.: Tumor differentiation; Adjuvant: adjuvant chemotherapy.

elevating RDW (21). In addition, the tumor microenvironment is characterized by a state of tumor-related systemic inflammation, thus accelerating tumor progression (22). As RDW reflects progressive cancer and tumor-related systemic inflammation, it was found to be associated with malnutrition, which has been shown to be correlated to poor response to treatment and worse prognosis (23).
With the steady increase in average life expectancy due to advances in medical sciences, gastric cancer is still the third leading cause of cancer-related deaths worldwide (24). It occurs predominantly in elderly people, with a peak incidence between 70 and 75 years of age. Because agespecific prognostic factors in patients with gastric cancer have not yet been described, patients were divided into two 
Table III. Relationships between RDW and clinicopathological features in 165 non-elderly patients with gastric cancer.

\begin{tabular}{|c|c|c|c|c|}
\hline \multirow[t]{2}{*}{ Characteristics } & \multirow{2}{*}{$\begin{array}{c}\text { Total } \\
\text { patients }\end{array}$} & \multicolumn{2}{|c|}{ RDW } & \multirow[t]{2}{*}{$p$-Value } \\
\hline & & $\begin{array}{c}<50 \\
(\mathrm{n}=145)\end{array}$ & $\begin{array}{c}\geq 50 \\
(\mathrm{n}=20)\end{array}$ & \\
\hline Age (years old) & & $60.3 \pm 7.6$ & $62.6 \pm 5.7$ & 0.2027 \\
\hline Gender & & & & 0.1122 \\
\hline Male & 115 & $98(67.6)$ & $17(85.0)$ & \\
\hline Female & 50 & $47(32.4)$ & $3(15.0)$ & \\
\hline BMI & & $22.44 \pm 3.62$ & $22.46 \pm 4.80$ & 0.9886 \\
\hline WBC $(\mu \mathrm{l})$ & & $5927.0 \pm 1370.2$ & $5782.0 \pm 1299.9$ & 0.6559 \\
\hline $\mathrm{RBC}\left(\times 10^{4} \mu \mathrm{l}\right)$ & & $464.3 \pm 295.2$ & $386.8 \pm 73.3$ & 0.2447 \\
\hline Location of tumor & & & & 0.6691 \\
\hline EGJ & 4 & $4(2.8)$ & $0(0)$ & \\
\hline $\mathrm{U}$ & 32 & $28(19.3)$ & $4(20.0)$ & \\
\hline M & 79 & $71(49.0)$ & $8(40.0)$ & \\
\hline $\mathrm{L}$ & 50 & $42(29.0)$ & $8(40.0)$ & \\
\hline Tumor size $(\mathrm{cm})$ & & $4.15 \pm 2.82$ & $4.30 \pm 3.29$ & 0.8326 \\
\hline \multicolumn{5}{|l|}{ Procedure } \\
\hline \multicolumn{5}{|l|}{0.3867} \\
\hline LTG & 35 & $29(20.0)$ & $6(30.0)$ & \\
\hline LPG & 21 & $20(13.8)$ & $1(5.0)$ & \\
\hline L(A)DG & 109 & $96(66.2)$ & $13(65.0)$ & \\
\hline Tumor differentiation & & & & 0.3552 \\
\hline Well & 25 & $24(16.6)$ & $1(5.0)$ & \\
\hline Moderate & 51 & $45(31.0)$ & $6(30.0)$ & \\
\hline Poor & 89 & $76(52.4)$ & $13(65.0)$ & \\
\hline Depth of tumor & & & & 0.3045 \\
\hline T1a-1b & 97 & $88(60.7)$ & $9(45.0)$ & \\
\hline 2 & 18 & $16(11.0)$ & $2(10.0)$ & \\
\hline 3 & 18 & $16(11.0)$ & $2(10.0)$ & \\
\hline $4 a-4 b$ & 32 & $25(17.2)$ & $7(35.0)$ & \\
\hline Lymph node metastasis & & & & 0.0006 \\
\hline No & 115 & $106(73.1)$ & $9(45.0)$ & \\
\hline N1 & 13 & $11(7.6)$ & $2(10.0)$ & \\
\hline N2 & 16 & $9(6.2)$ & $7(35.0)$ & \\
\hline N3 & 21 & $19(13.1)$ & $2(10.0)$ & \\
\hline Pathological stage & & & & 0.1385 \\
\hline Ia-Ib & 107 & $98(67.6)$ & $9(45.0)$ & \\
\hline IIa-IIb & 22 & $18(12.4)$ & $4(20.0)$ & \\
\hline IIIa-IIIc & 36 & $29(20.0)$ & $7(35.0)$ & \\
\hline Operation time (min) & & $411.8 \pm 117.0$ & $487.9 \pm 163.3$ & 0.0106 \\
\hline Intraoperative & & & & \\
\hline blood loss (ml) & & $164.3 \pm 359.0$ & $314.5 \pm 436.2$ & 0.0897 \\
\hline CEA (ng/ml) & & $4.16 \pm 7.57$ & $5.96 \pm 6.10$ & 0.313 \\
\hline Albumin (g/dl) & & $4.16 \pm 0.49$ & $3.61 \pm 0.830$ & $<0.0001$ \\
\hline $\mathrm{CRP}(\mathrm{mg} / \mathrm{l})$ & & $0.227 \pm 0.678$ & $0.411 \pm 0.666$ & 0.2562 \\
\hline Adjuvant chemotherapy & & & & 0.0577 \\
\hline Yes & 52 & $42(29.0)$ & $10(50.0)$ & \\
\hline No & 113 & $103(71.0)$ & $10(50.0)$ & \\
\hline
\end{tabular}

age groups to determine the age-specific prognostic values of the RDW (25). In non-elderly patients, a significant association was found between high RDW and unfavorable OS, but not with CSS. On the other hand, elderly patients showed a significant association between high RDW and
Table IV. Relationships between RDW and clinicopathological features 201 elderly patients with gastric cancer.

\begin{tabular}{|c|c|c|c|c|}
\hline \multirow[t]{2}{*}{ Characteristics } & \multirow{2}{*}{$\begin{array}{c}\text { Total } \\
\text { patients }\end{array}$} & \multicolumn{2}{|c|}{ RDW } & \multirow[t]{2}{*}{$p$-Value } \\
\hline & & $\begin{array}{c}<50 \\
(\mathrm{n}=137)\end{array}$ & $\begin{array}{c}\geq 50 \\
(\mathrm{n}=64)\end{array}$ & \\
\hline Age (years) & & $78.7 \pm 5.3$ & $79.8 \pm 5.4$ & 0.1714 \\
\hline Gender & & & & 0.318 \\
\hline Male & 138 & $91(66.4)$ & $47(73.4)$ & \\
\hline Female & 63 & $46(33.6)$ & 17 (26.6) & \\
\hline BMI & & $22.33 \pm 3.20$ & $22.54 \pm 3.24$ & 0.66 \\
\hline $\mathrm{WBC}(\mu \mathrm{l})$ & & $5720.1 \pm 1401.9$ & $5477.5 \pm 1714.6$ & 0.2893 \\
\hline $\operatorname{RBC}\left(\times 10^{4} \mu \mathrm{l}\right)$ & & $414.4 \pm 50.5$ & $429.2 \pm 573.1$ & 0.7641 \\
\hline Location of tumor & & & & 0.2237 \\
\hline EGJ & 7 & $3(2.2)$ & $4(6.3)$ & \\
\hline $\mathrm{U}$ & 35 & $21(15.3)$ & $14(21.9)$ & \\
\hline M & 84 & $62(45.3)$ & $22(34.4)$ & \\
\hline $\mathrm{L}$ & 75 & $51(37.2)$ & $24(37.5)$ & \\
\hline Tumor size $(\mathrm{cm})$ & & $4.78 \pm 3.18$ & $5.95 \pm 3.31$ & 0.0167 \\
\hline \multicolumn{5}{|l|}{ Procedure } \\
\hline \multicolumn{5}{|l|}{0.1833} \\
\hline LTG & 141 & $101(73.7)$ & $40(62.5)$ & \\
\hline LPG & 16 & $11(8.0)$ & $5(7.8)$ & \\
\hline L(A)DG & 44 & $25(18.2)$ & $19(29.7)$ & \\
\hline Tumor differentiation & & & & 0.1201 \\
\hline Well & 46 & $37(27.0)$ & $9(14.1)$ & \\
\hline Moderate & 82 & $52(38.0)$ & $30(46.9)$ & \\
\hline Poor & 73 & $48(35.0)$ & $25(39.1)$ & \\
\hline Depth of tumor & & & & 0.0001 \\
\hline $\mathrm{T} 1 \mathrm{a}-1 \mathrm{~b}$ & 96 & $78(56.9)$ & $18(28.1)$ & \\
\hline 2 & 30 & $22(16.1)$ & $8(12.5)$ & \\
\hline 3 & 35 & $18(13.1)$ & $17(26.6)$ & \\
\hline $4 a-4 b$ & 40 & $19(13.9)$ & $21(32.8)$ & \\
\hline Lymph node metastasis & & & & 0.0312 \\
\hline No & 131 & $98(71.5)$ & $33(51.6)$ & \\
\hline N1 & 27 & $13(9.5)$ & $14(21.9)$ & \\
\hline $\mathrm{N} 2$ & 26 & $16(11.7)$ & $10(15.6)$ & \\
\hline N3 & 17 & $10(7.3)$ & $7(10.9)$ & \\
\hline Pathological stage & & & & $<0.0001$ \\
\hline Ia-Ib & 217 & $91(66.4)$ & $20(31.3)$ & \\
\hline IIa-IIb & 65 & $22(16.1)$ & $22(34.4)$ & \\
\hline IIIa-IIIc & 86 & $24(17.5)$ & $22(34.4)$ & \\
\hline Operation time (min) & & $412.3 \pm 113.7$ & $418.9 \pm 117.7$ & 0.7056 \\
\hline Intraoperative & & & & \\
\hline blood loss (ml) & & $159.6 \pm 232.5$ & $455.3 \pm 911.1$ & 0.0005 \\
\hline CEA (ng/ml) & & $4.78 \pm 9.08$ & $7.44 \pm 21.87$ & 0.2244 \\
\hline Albumin (g/dl) & & $3.90 \pm 0.50$ & $3.49 \pm 0.67$ & $<0.0001$ \\
\hline $\mathrm{CRP}(\mathrm{mg} / \mathrm{l})$ & & $0.353 \pm 0.937$ & $0.694 \pm 1.611$ & 0.0608 \\
\hline Adjuvant Chemotherapy & & & & 0.8073 \\
\hline Yes & 45 & 30 & 15 & \\
\hline No & 156 & 107 & 49 & \\
\hline
\end{tabular}

unfavorable OS and CSS. This difference was possibly due to the positive association between RDW and TNM pStage in elderly but not in non-elderly patients. Because RDW has been reported to be more closely associated with all-cause mortality, including chronic lower respiratory tract infection- 
a

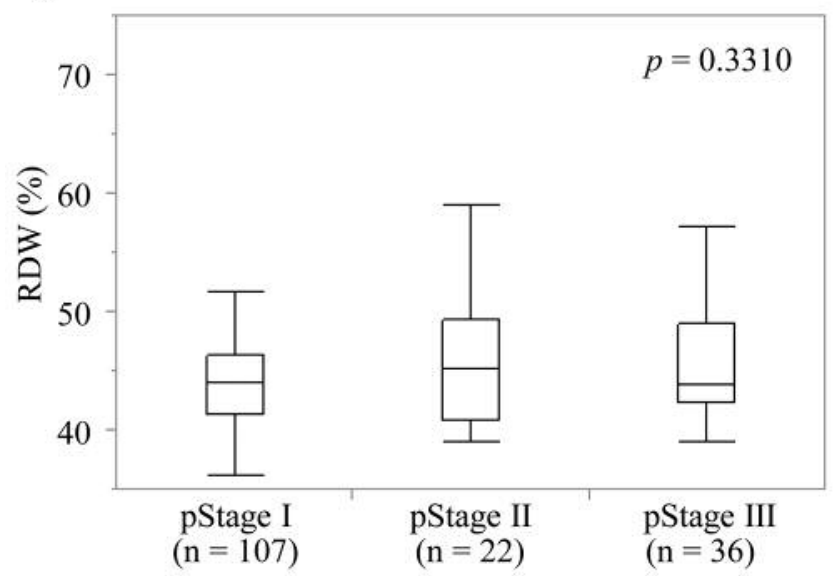

b

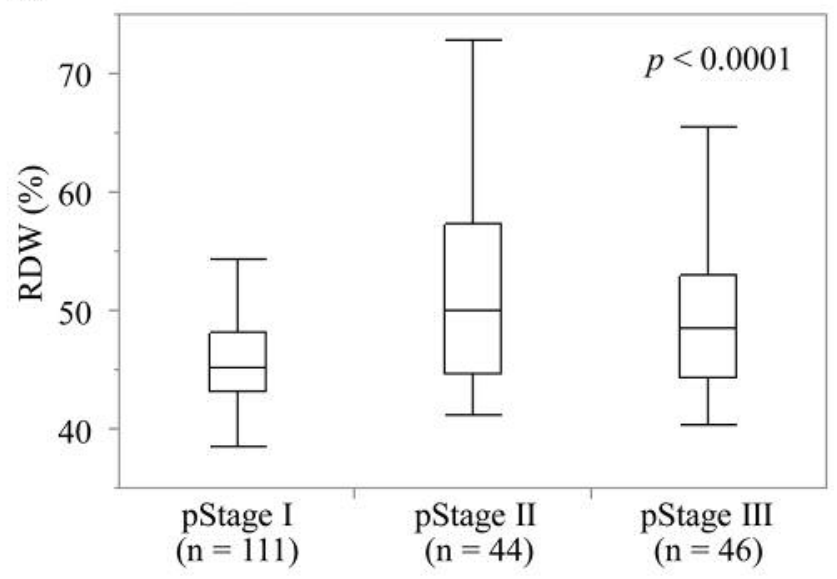

Figure 3. RDW values of all gastric cancer patients according to pStage. (a) Non-elderly patients ( $n=165)$. (b) Elderly patients ( $n=201)$. In each box plot, the lower and upper ends represent the 25th and 75th percentiles, respectively. Capped bars indicate the minimum and maximum values, respectively and the line inside the box represents the median $R D W$ value.

a

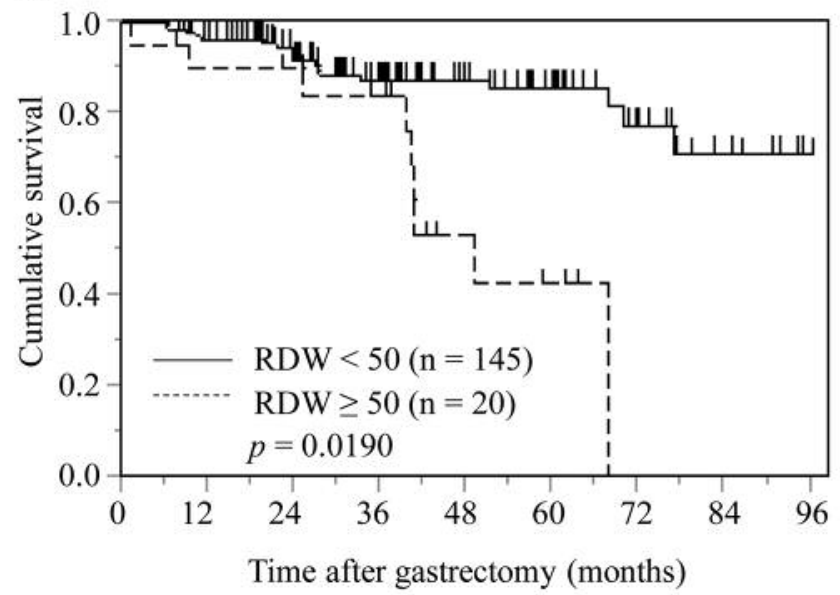

b

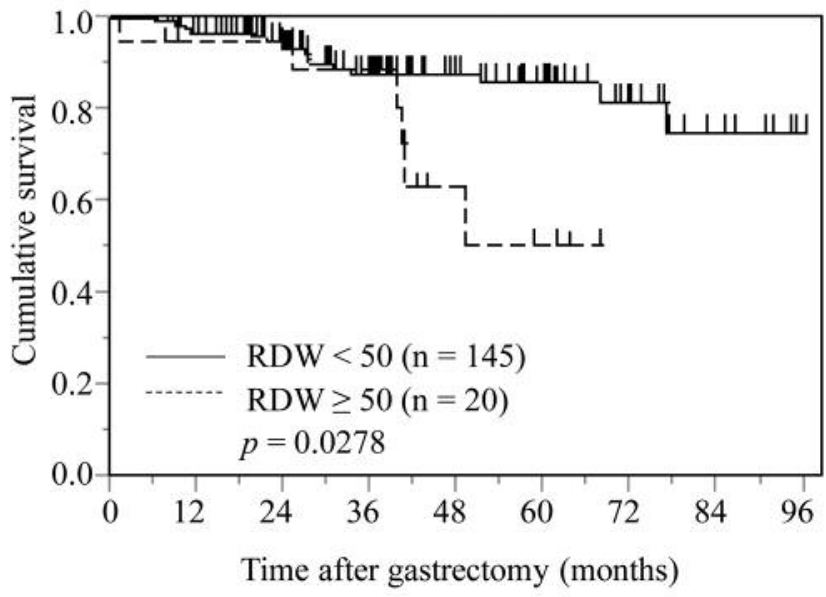

Figure 4. Kaplan-Meier curves of survival based on RDW of 165 non-elderly patients with gastric cancer. (a) Overall survival, (b) cancer-specific survival.

related deaths and cardiovascular mortality, RDW could be a surrogate for poor physical condition of elderly patients (26-28). In this study, RDW cut off value set at $>50$ by our hospital laboratory routine use. Although RDW has shown to be one of the prognostic factors of esophageal cancer, it was not in elderly patients (5). This is the first report suggesting that RDW could have a prognostic value in elderly patient with gastric cancer. However, because the number of people with high RDW in the non-elderly group is small (only 20 people), there is a possibility that this consideration is subject to a large bias. To define the significance of RDW according to age, studies with larger sample size are required.

This study had several limitations that should be discussed. First, the main limitation of the present study was its retrospective nature and the fact that some of the patient characteristics may have been biased since only 20 patients had RDW-SD of >50 in the non-elderly group. Second, this study was a single center study, and the number of analyzed patients was relatively low. Third, this trial had a short follow-up of survival, therefore there were many early censored cases in survival analysis. Despite these limitations, 
Table V. Univariate and multivariate analyses for prognostic factors in non-elderly gastric cancer patients.

\begin{tabular}{|c|c|c|c|c|c|c|c|c|c|c|c|c|}
\hline \multirow[t]{3}{*}{ Variables } & \multicolumn{6}{|c|}{ Overall survival } & \multicolumn{6}{|c|}{ Cancer-specific survival } \\
\hline & \multicolumn{3}{|c|}{ Univariate } & \multicolumn{3}{|c|}{ Multivariate } & \multicolumn{3}{|c|}{ Univariate } & \multicolumn{3}{|c|}{ Multivariate } \\
\hline & $\mathrm{HR}$ & $95 \% \mathrm{CI}$ & $p$-Value & HR & $95 \% \mathrm{CI}$ & $p$-Value & HR & $95 \% \mathrm{CI}$ & $p$-Value & HR & $95 \% \mathrm{CI}$ & $p$-Value \\
\hline \multicolumn{13}{|l|}{ Gender } \\
\hline Female/male & 2.466 & $0.947-8.416$ & 0.0661 & & & & 1.485 & $0.586-4.523$ & 0.4221 & & & \\
\hline \multicolumn{13}{|l|}{ pStage } \\
\hline $\begin{array}{r}\text { I, II/III } \\
<0.0001\end{array}$ & 10.383 & $34.675-24.802$ & $<0.0001$ & 11.856 & $3.791-38.066$ & $<0.0001$ & 21.656 & $7.983-75.612$ & $<0.0001$ & 25.871 & 5.958-118.999 & \\
\hline $\begin{array}{c}\text { Tumor size } \\
<5 / \geq 5\end{array}$ & 2.866 & $1.339-6.267$ & 0.007 & 2.106 & $0.901-5.044$ & 0.0857 & 3.827 & $1.637-9.590$ & 0.0019 & 1.669 & $0.677-4.398$ & 0.2697 \\
\hline \multicolumn{13}{|l|}{ RDW } \\
\hline$<50 / \geq 50$ & 4.088 & $1.718-9.150$ & 0.0022 & 3.4 & $1.339-8.154$ & 0.0114 & 2.785 & $0.989-6.900$ & 0.0523 & & & \\
\hline \multicolumn{13}{|l|}{ CEA } \\
\hline$<5.0 / \geq 5.0$ & 2.077 & $0.887-4.530$ & 0.0895 & & & & 1.972 & $0.749-4.701$ & 0.1597 & & & \\
\hline \multicolumn{13}{|l|}{ Diff. } \\
\hline Well \& mod/poor & 1.565 & $0.727-3.554$ & 0.2551 & & & & 1.946 & $0.819-5.105$ & 0.1341 & & & \\
\hline \multicolumn{13}{|l|}{ BMI } \\
\hline$\geq 18.5 /<18.5$ & 0.445 & $0.1815-1.331$ & 0.1348 & & & & 0.661 & $0.225-2.814$ & 0.5261 & & & \\
\hline \multicolumn{13}{|l|}{ Adjuvant } \\
\hline No/Yes & 3.184 & $1.472-7.053$ & 0.0034 & 0.513 & $0.184-1.513$ & 0.2218 & 6.598 & $2.668-18.714$ & $<0.0001$ & 1.53 & $0.381-5.003$ & 0.527 \\
\hline
\end{tabular}

Diff.: Tumor differentiation; Adjuvant: adjuvant chemotherapy.

Table VI. Univariate and multivariate analyses for prognostic factors in elderly gastric cancer patients.

\begin{tabular}{|c|c|c|c|c|c|c|c|c|c|c|c|c|}
\hline \multirow[t]{3}{*}{ Variables } & \multicolumn{6}{|c|}{ Overall survival } & \multicolumn{6}{|c|}{ Cancer-specific survival } \\
\hline & \multicolumn{3}{|c|}{ Univariate } & \multicolumn{3}{|c|}{ Multivariate } & \multicolumn{3}{|c|}{ Univariate } & \multicolumn{3}{|c|}{ Multivariate } \\
\hline & HR & $95 \% \mathrm{CI}$ & $p$-Value & HR & $95 \% \mathrm{CI}$ & $p$-Value & HR & $95 \% \mathrm{CI}$ & $p$-Value & HR & $95 \% \mathrm{CI}$ & $p$-Value \\
\hline \multicolumn{13}{|l|}{ Gender } \\
\hline Female/male & 1.192 & $0.675-2.205$ & 0.553 & & & & 1.295 & $0.488-4.041$ & 0.6168 & & & \\
\hline \multicolumn{13}{|l|}{ pStage } \\
\hline I, II/III & 1.941 & $1.085-3.369$ & 0.0262 & 1.16 & $0.603-2.273$ & 0.6595 & 5.503 & $2.166-14.964$ & 0.0004 & 2.114 & $0.689-7.411$ & 0.1959 \\
\hline \multicolumn{13}{|l|}{ Tumor size } \\
\hline$<5 / \geq 5$ & 1.84 & $1.064-3.263$ & 0.0289 & 1.36 & $0.714-2.629$ & 0.3517 & 5.6 & $1.848-24.179$ & 0.0014 & 2.704 & $0.681-13.243$ & 30.1597 \\
\hline \multicolumn{13}{|l|}{ RDW } \\
\hline$<50 / \geq 50$ & 2.794 & $1.616-4.844$ & 0.0003 & 2.562 & $1.447-4.547$ & 0.0014 & 3.939 & $1.549-10.722$ & 0.0041 & 2.832 & $1.069-7.958$ & 0.0363 \\
\hline \multicolumn{13}{|l|}{ CEA } \\
\hline$<5.0 / \geq 5.0$ & 1.79 & $0.999-3.117$ & 0.0503 & & & & 2.462 & $0.940-6.244$ & 0.0658 & & & \\
\hline \multicolumn{13}{|l|}{ Diff. } \\
\hline Well \& mod/poor & 2.165 & $1.255-3.764$ & 0.0057 & 1.971 & $1.128-3.467$ & 0.0173 & 1.862 & $0.726-4.773$ & 0.1911 & & & \\
\hline \multicolumn{13}{|l|}{ BMI } \\
\hline$\geq 18.5 /<18.5$ & 0.758 & $0.350-1.982$ & 0.5383 & & & & 0.806 & $0.229-5.098$ & 0.78 & & & \\
\hline \multicolumn{13}{|l|}{ Adjuvant } \\
\hline No/Yes & 1.16 & $0.615-2.073$ & 0.634 & & & & 2.996 & $1.170-7.675$ & 0.023 & 1.685 & $0.608-4.685$ & 0.3114 \\
\hline
\end{tabular}

Diff.: Tumor differentiation; Adjuvant: adjuvant chemotherapy.

the present study provides useful information about not only non-elderly but also elderly gastric cancer patients. In addition, this study was focused on just the preoperative RDW values and did not evaluate the dynamic changes in
RDW during the course of the disease, since postoperative value may depend on many factors such as measurement timing. Finally, the biological and molecular mechanisms that can explain the prognostic ability of systemic 


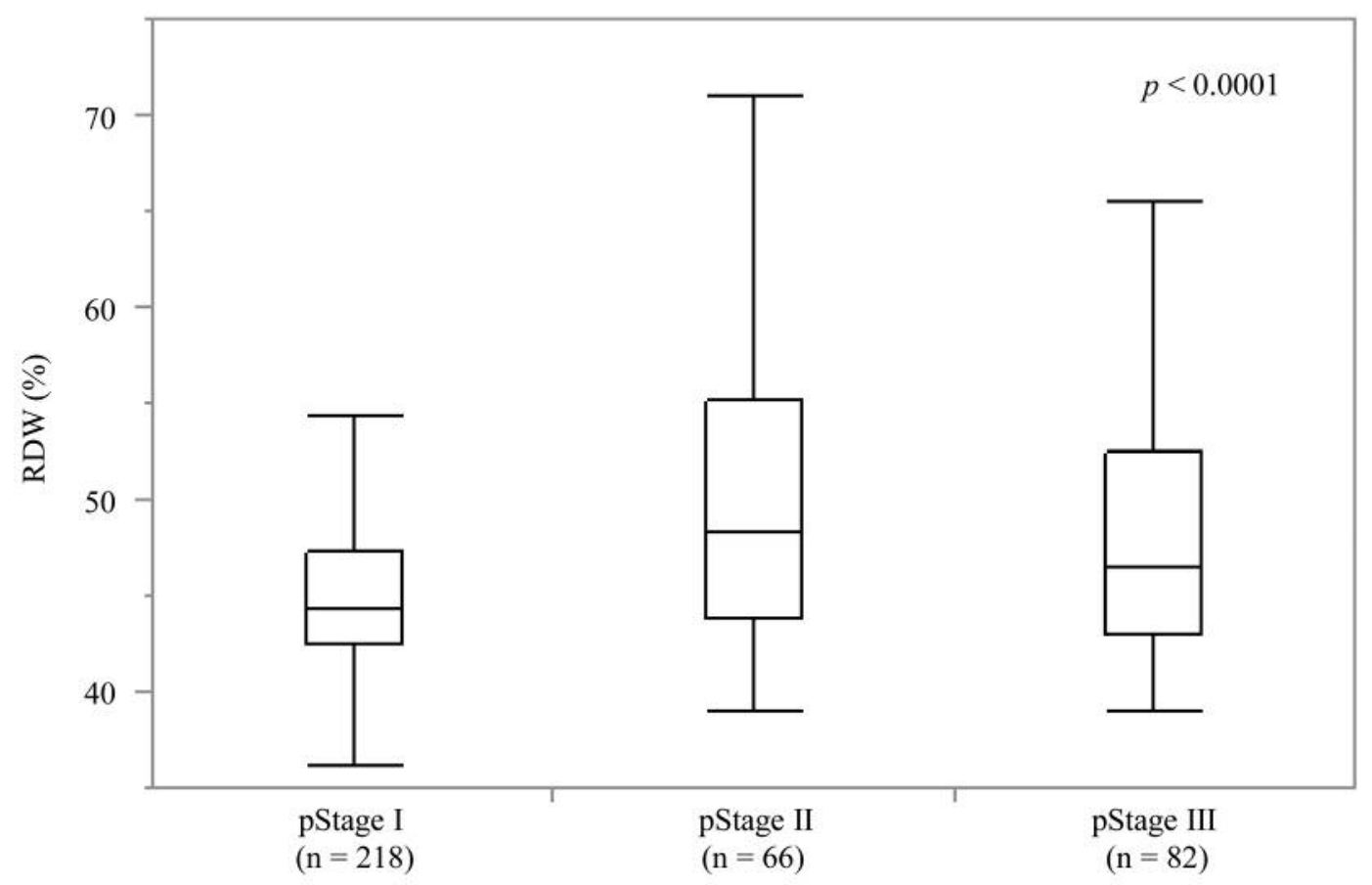

Figure 5. Kaplan-Meier curves of survival based on RDW of 201 elderly patients with gastric cancer. (a) Overall survival, (b) cancer-specific survival.

inflammatory factors are yet to be elucidated. Thus, Largescale multicenter collaborative studies should be conducted to confirm our preliminary findings.

Despite the above limitations, RDW is easy to measure routinely because of its low cost, convenience, and reproducibility. The present study provides evidence that the preoperative RDW is a promising independent prognostic factor in patients with gastric cancer. Nevertheless, further studies are required on the role of RDW values in the identification of patients at high risk of recurrence accurately, selection-appropriate treatment strategies, and treatment outcomes in gastric cancer patients.

\section{Conflicts of Interest}

The Authors declare that they have no competing interests.

\section{Authors' Contributions}

$\mathrm{NH}$ was the lead author and conceived this study. YF, SK, TY, RH, TT and YK collected data and performed analysis. YT reviewed paper. All authors read and approved the final manuscript.

\section{References}

1 Cancer Research UK [Internet]. Available: http:// www.cancerre searchuk.org/health-professional/cancer-statistics/statistics
2 Hartgrink HH, Jansen EP, van Grieken NC and van de Velde CJ: Gastric cancer. Lancet 374(9688): 477-490, 2009. PMID: 19625077. DOI: 10.1016/S0140-6736(09)60617-6

3 Roberts GT and El Badawi SB: Red blood cell distribution width index in some hematologic diseases. Am J Clin Pathol 83(2): 222-226, 1985. PMID: 3969961.

4 Loprinzi PD and Hall ME: Physical activity and dietary behavior with red blood cell distribution width. Physiol Behav 149: 35-38, 2015. PMID: 26003494. DOI: 10.1016/j.physbeh. 2015.05.018

5 Hirahara N, Matsubara T, Kawahara D, Mizota Y, Ishibashi S and Tajima Y: Prognostic value of hematological parameters in patients undergoing esophagectomy for esophageal squamous cell carcinoma. Int J Clin Oncol 21(5): 909-919, 2016. PMID: 27154178. DOI: 10.1007/s10147-016-0986-9

6 Iriyama N, Hatta Y, Kobayashi S, Uchino Y, Miura K, Kurita D, Kodaira H, Takahashi H, Iizuka Y, Inoue M and Takei M: Higher red blood cell distribution Width is an adverse prognostic factor in chronic-phase chronic myeloid leukemia patients treated with tyrosine kinase inhibitors. Anticancer Res 35(10): 5473-5478, 2015. PMID: 26408711.

7 Ay S, Eryilmaz MA, Aksoy N, Okus A, Unlu Y and Sevinc B: Is early detection of colon cancer possible with red blood cell distribution width? Asian Pac J Cancer Prev 16(2): 753-756, 2015. PMID: 25684520

8 Auezova R, Ryskeldiev N, Doskaliyev A, Kuanyshev Y, Zhetpisbaev B, Aldiyarova N, Ivanova N, Akshulakov S and Auezoval L: Association of preoperative levels of selected blood inflammatory markers with prognosis in gliomas. Onco Targets Ther 9: 6111-6117, 2016. PMID: 27785058. DOI: 10.2147/ OTT.S113606 
9 Wang FM, Xu G, Zhang Y and Ma LL: Red cell distribution width is associated with presence, stage, and grade in patients with renal cell carcinoma. Dis Markers 2014: 860419, 2014. PMID: 25580051. DOI: 10.1155/2014/860419

10 Böger C, Behrens HM, Krüger S and Röcken C: The novel negative checkpoint regulator VISTA is expressed in gastric carcinoma and associated with PD-L1/PD-1: A future perspective for a combined gastric cancer therapy?. Oncoimmunology 6(4): e1293215, 2017. PMID: 28508701. DOI: 10.1080/2162402X.2017.1293215

11 Girardi DM, Silva ACB, Rêgo JFM, Coudry RA and Riechelmann RP: Unraveling molecular pathways of poorly differentiated neuroendocrine carcinomas of the gastroenteropancreatic system: A systematic review. Cancer Treat Rev 56: 28-35, 2017. PMID: 28456055. DOI: $10.1016 /$ j.ctrv.2017.04.002

12 Sugimoto R, Sugai T, Habano W, Endoh M, Eizuka M, Yamamoto E, Uesugi N, Ishida K, Kawasaki T, Matsumoto T and Suzuki H: Clinicopathological and molecular alterations in early gastric cancers with the microsatellite instability-high phenotype. Int J Cancer 138(7): 1689-1697, 2016. PMID: 26538087. DOI: $10.1002 / \mathrm{ijc} .29916$

13 Japanese Gastric Cancer Association. Japanese gastric cancer treatment guidelines 2010 (ver.3). Gastric Cancer 14(2): 113123, 2011. PMID: 21573742. DOI: 10.1007/s10120-011-0042-4

14 Whisler S and Dahlgren C: Performance evalusation of the Sysmex pocH-100i automated hematology analyzer. Lab Hematol 11(2): 107-117, 2005. PMID: 16024334. DOI: 10.1532/ LH96.04068

15 Japanese Gastric Cancer Association: Japanese classification of gastric carcinoma 3rd English edition. Gastric Cancer 14: 101112, 2011. PMID: 21573743. DOI: 10.1007/s10120-011-0041-5

16 Hirahara N, Matsubara T, Kawahara D, Nakada S, Ishibashi S and Tajima Y: Prognostic significance of preoperative inflammatory response biomarkers in patients undergoing curative thoracoscopic esophagectomy for esophageal squamous cell carcinoma. Eur J Surg Oncol 43(2): 493-501, 2017. PMID: 28034501. DOI: $10.1016 /$ j.ejso.2016.11.018

17 Katheder NS and Rusten TE: Microenvironment and tumors-a nurturing relationship. Autophagy 13(7): 1241-1243, 2017. PMID: 28632995. DOI: 10.1080/15548627.2017.1310361

18 Chen X, Ying X, Wang X, Wu X, Zhu Q and Wang X: Exosomes derived from hypoxic epithelial ovarian cancer deliver microRNA-940 to induce macrophage M2 polarization. Oncol Rep 38(1): 522-528, 2017. PMID: 28586039. DOI: 10.3892/or. 2017.5697

19 de Gonzalo-Calvo D, de Luxán-Delgado B, Rodríguez-González S, García-Macia M, Suárez FM, Solano JJ, Rodríguez-Colunga MJ and Coto-Montes A: Interleukin 6, soluble tumor necrosis factor receptor I and red blood cell distribution width as biological markers of functional dependence in an elderly population: a translational approach. Cytokine 58(2): 193-198, 2012. PMID: 22309694. DOI: 10.1016/j.cyto.2012.01.005
$20 \mathrm{He}$ Y, Liu C, Zeng Z, Ye W, Lin J and Ou Q: Red blood cell distribution width: a potential laboratory parameter for monitoring inflammation in rheumatoid arthritis. Clin Rheumatol 37(1): 161167, 2018. PMID: 29101675. DOI: 10.1007/s 10067-017-3871-7

21 Forhecz Z, Gombos T, Borgulya G, Pozsonyi Z, Prohászka Z and Jánoskuti L: Red cell distribution width in heart failure: prediction of clinical events and relationship with markers of ineffective erythropoiesis, inflammation, renal function, and nutritional state. Am Heart J 158(4): 659-666, 2009. PMID: 19781428. DOI: 10.1016/j.ahj.2009.07.024

22 Kumari N, Dwarakanath BS, Das A and Bhatt AN: Role of interleukin-6 in cancer progression and therapeutic resistance. Tumour Biol 37(9): 11553-11572, 2016. PMID: 27260630. DOI: 10.1007/s13277-016-5098-7

23 Hébuterne X, Lemarié E, Michallet M, de Montreuil CB, Schneider SM and Goldwasser F: Prevalence of malnutrition and current use of nutrition support in patients with cancer. JPEN J Parenter Enteral Nutr 38(2): 196-204, 2014. PMID: 24748626. DOI: $10.1177 / 0148607113502674$

24 Torre LA, Siegel RL, Ward EM and Jemal A: Global cancer incidence and mortality rates and trends-An update. Cancer Epidemiol Biomarkers Prev 25(1): 16-27, 2016. PMID: 26667886. DOI: 10.1158/1055-9965.EPI-15-0578

25 Saif MW, Makrilia N, Zalonis A, Merikas M and Syrigos K: Gastric cancer in the elderly: an overview. Eur J Surg Oncol 36(8): 709-717, 2010. PMID: 20542657. DOI: 10.1016/ j.ejso.2010.05.023

26 Bello S, Fandos S, Lasierra AB, Mincholé E, Panadero C, Simon AL, Gavin O, De Pablo F, Menendez R and Torres A: Red blood cell distribution width [RDW] and long-term mortality after community-acquired pneumonia. A comparison with proadrenomedullin. Respir Med 109(9): 1193-206, 2015. PMID: 26205553. DOI: 10.1016/j.rmed.2015.07.003

27 Yeh CF, Chen KF, Ye JJ and Huang CT: Derivation of a clinical prediction rule for bloodstream infection mortality of patients visiting the emergency department based on predisposition, infection, response, and organ dysfunction concept. J Microbiol Immunol Infect 47(6): 469-477, 2014. PMID: 23968756. DOI: 10.1016/j.jmii.2013.06.012

$28 \mathrm{Ku}$ NS, Kim HW, Oh HJ, Kim YC, Kim MH, Song JE, Oh DH, Ahn JY, Kim SB, Jeong SJ, Han SH, Kim CO, Song YG, Kim JM and Choi JY: Red blood cell distribution width is an independent predictor of mortality in patients with gramnegative bacteremia. Shock 38(2): 123-127, 2012. PMID: 22683729. DOI: 10.1097/SHK.0b013e31825e2a85

Received April 9, 2019 Revised April 30, 2019 Accepted May 2, 2019 